\title{
ENTROPY MANAGEMENT OF GAUSSIAN STOCHASTIC SYSTEMS
}

\author{
A. N. Tyrsin ${ }^{1}$, at2001@yandex.ru, \\ G. G. Gevorgyan ${ }^{1}$, garnik.ggg@gmail.com. \\ 1 Ural Federal University named after the first President of Russia B.N. Yeltsin, \\ Ekaterinburg, Russian Federation.
}

Two approaches to the entropy management of Gaussian stochastic system are considered. The first approach is scalar and implements the concept of "growth points". In this case the problem of maximizing (increasing) or minimizing (decreasing) the system entropy is solved. The second approach is the vector management, allowing to ensure effective changing of the entropy of two-dimensional vector, the components of which are randomness and self-organization entropies. For vector control an optimization problem on the conditional extremum is formulated. This problem can be solved using penalty methods. It is shown that the vector management of entropy for a number of cases has advantages compared to the scalar management. Examples of entropy models of real stochastic systems are provided.

Keywords: differential entropy, multidimensional random variable, Gaussian stochastic system, covariance matrix, management, randomness, self-organization.

\section{Introduction}

A number of real systems can be classified as complex multidimensional stochastic systems. The main important feature of these systems is having multiple elements that are intricately linked. In situations like this, the multidimensional stochastic system is often being modeled as a random vector.

One of the perspectives of modeling complex stochastic systems is based on the application of entropy. It is known that entropy is a fundamental property of all systems with an ambiguous or probabilistic behavior [1] . The concept of entropy is rather flexible and it can be clearly interpreted in terms of that specific area, where it is applied. It is being widely used in modern science to describe the structural organization and disorganization, the degree of destruction of the connections between the elements of the system [2-8].

Let's take a complex stochastic system $\mathrm{S}$ as a multidimensional continuous random variable $\boldsymbol{Y}=\left(Y_{1}, Y_{2}, \ldots, Y_{m}\right)$. Each $Y_{i}$ element of the vector $\mathbf{Y}$ is a one-dimensional random variable which is characterizing the functioning of the particular element of the system under study. Those elements can be either interdependent or independent of each other.

In [9] the differential entropy of random vector $\mathbf{Y}$ with $p_{Y}\left(x_{1}, \ldots, x_{m}\right)$ joint probability density was introduced:

$$
H(\boldsymbol{Y})=-\int_{-\infty}^{+\infty} \ldots \int_{-\infty}^{+\infty} p_{\boldsymbol{Y}}\left(x_{1}, x_{2}, \ldots, x_{m}\right) \log p_{\boldsymbol{Y}}(\boldsymbol{x}) d x_{1} d x_{2} \ldots t x_{m}
$$

Let's consider the approach to the management of multidimensional stochastic systems using differential entropy on the example of Gaussian systems. 


\section{The Entropy Model of a Gaussian Stochastic System}

We take that the $\boldsymbol{Y}=\left(Y_{1}, Y_{2}, . ., Y_{m}\right)$ random variable has a multivariate normal distribution with a $\Sigma=\left\{\sigma_{\mathrm{ij}}\right\}_{m \times m}$ covariance matrix with its elements $\sigma_{\mathrm{ij}}=\operatorname{cov}\left(Y_{i}, Y_{j}\right)$ is the covariance between $Y_{i}$ and $Y_{j}$ random variables, $\sigma_{\mathrm{ii}}=\sigma_{i}^{2}$ is the variance of random variable $Y_{i}, i, j=1,2, \ldots, m$.

For a multidimensional normally distributed random variable $\boldsymbol{Y}$ the differential entropy (the entropy from now on) $H(\boldsymbol{Y})$ is equal to [10]:

$$
H(\boldsymbol{Y})=\frac{1}{2} \log \left[(2 \pi e)^{m}|\Sigma|\right]
$$

The entropy (1), being a functional from the set of probability densities of random variable $\boldsymbol{Y}$, is a number. And therefore it cannot be counted as an adequate mathematical model of a multidimensional system. Let's represent the (1) in the form [11]:

$$
H(\boldsymbol{Y})=H(\boldsymbol{Y})_{V}+H(\boldsymbol{Y})_{R}
$$

where

$$
\begin{gathered}
H(\boldsymbol{Y})_{V}=\sum_{k=1}^{m} H\left(Y_{k}\right), \quad H\left(Y_{i}\right)=\frac{1}{2} \log \left[(2 \pi e) \sigma_{i}^{2}\right], \\
i=1,2, \ldots, m, \quad H(\boldsymbol{Y})_{R}=\frac{1}{2} \log (|\boldsymbol{R}|),
\end{gathered}
$$

$|\boldsymbol{R}|$ is the determinant of the correlation matrix $\boldsymbol{R}=\left\{r_{i j}\right\}_{m \times m}$ of the random variable $\boldsymbol{Y}$, $r_{i j}=\frac{\sigma_{i j}}{\sqrt{\sigma_{i i} \sigma_{j j}}}$.

The first term of (2) is the sum of differential entropies and is equal to the joint entropy in the case of mutual independence of the $Y_{i}$ components of the random variable $\boldsymbol{Y}$. It can be conditionally called randomness entropy. The second term of (2) is equal to the entropy which occurs due to the correlations between the elements of the system. It can be conditionally called self-organization entropy.

\section{The Entropy Management Based on the Concept of Growth Points}

Many authors $[3,12,13]$ note that the increase of the system functioning efficiency can be examined from the perspective of increasing or decreasing its entropy. Therefore, the entropy model (2) allows us to solve the problems of effective management of the stochastic system. The most obvious option of that management is the provision of a control influence on the system in order to increase or decrease its entropy. An increase of the entire system entropy can be achieved either due to the growth of uncertainty (variances) of one or several elements or due to the stagnation of the correlations degree between the elements (increasing the determinant of the correlation matrix). A decrease of the entire system entropy, on the other hand, is achieved by reducing the variances of its elements or by increasing the correlation degree between the elements.

Note that we owe some resource (energy) to impact the system during the open system management. One of the key areas for effective solution of such problems is the concept of 
"growth points" first proposed by François Perroux [14]. The concept of "growth points" allows to highlight those system elements which are significantly sensitive to the entropy changes, and at very limited, small amount of dedicated resource to use it most efficiently. As the system is a set of interrelated elements, an impact on a well matched point will trigger a chain of processes that will lead to the greatest entropy change of the entire system.

Definition 1. By the growth point of the system, in the problem of achieving an increase (decrease) of the $\boldsymbol{Y}=\left(Y_{1}, Y_{2}, . ., Y_{m}\right)$ random vector's entropy by the way of impacting on its elements variances, we will understand the component $Y_{i}$, the increase (decrease) of which $\sigma_{i}^{2}$ variance by a fixed amount will lead to the greatest increase (decrease) of the $H(\boldsymbol{Y})$ entropy, compared with the other components $Y_{i}, i \neq j$.

Definition 2. By the growth points of the system, in the problem of achieving an increase (decrease) of the $\boldsymbol{Y}=\left(Y_{1}, Y_{2}, . ., Y_{m}\right)$ random vector's entropy by the way of impacting on the $r_{\mathrm{ij}}$ correlations between its elements, we will understand the pair of the components $Y_{i}$ and $Y_{j}, i \neq j$, the change of $r_{\mathrm{ij}}$ of which by a fixed amount will lead to the greatest increase (decrease) of the $H(\boldsymbol{Y})$ entropy, compared with the other pairs of components.

Depending on the purpose of management and on the available resources, it is possible to formulate various objectives of changing the system entropy [15]: changing the entropy to its maximum or minimum value under the existing constraints; changing the entropy towards its increase or decrease.

Consider the problem of maximizing the entropy of a stochastic system.

We need to identify one growth point. Here is our problem:

$$
\left\{\begin{array}{l}
0,5 \log \left[(2 \pi e)^{m}\left(|\Sigma|+\sigma_{U}^{2} M_{i i}\right)\right] \rightarrow \max _{i \in[1, m]} \\
\sigma_{U}^{2}=\sigma^{2}, \\
\operatorname{cov}\left(U, Y_{i}\right)=0, \quad i=1,2, \ldots, m .
\end{array}\right.
$$

The problem (3) will allow to achieve the maximum increase in entropy via optimally choosing the corresponding $Y_{i}$ element of the system and adding a random Gaussian variable $U$ with a given variance to it.

If there is a chance of a simultaneous influence on several elements of the system, the problem (3) can be complicated. In this case we will additively impact on the Gaussian $\boldsymbol{Y}$ system with an additional vector, components of which don't correlate with the elements of the initial random variable. Then we'll get a problem of maximizing the entropy growth of the multidimensional random variable by adding normally distributed random variables $U_{i}, U_{i} \sim N\left(a_{U_{i}}, \sigma_{U_{i}}^{2}\right),(i=1,2, \ldots m)$, to the components $Y_{i}$ of $\boldsymbol{Y}$ random vector. The problem has the following form:

$$
\left\{\begin{array}{l}
\frac{1}{2} \log \left[(2 \pi e)^{m}\left|\Sigma^{*}\right|\right] \rightarrow \max _{\sigma_{U_{i}}^{2}}, \\
\sum_{i=1}^{m} \sigma_{U_{i}}^{2}=\sigma^{2}, \\
\operatorname{cov}\left(U_{i}, Y_{j}\right)=0, \quad i, j=1,2, \ldots, m, \\
\operatorname{cov}\left(U_{i}, U_{j}\right)=0, \quad i, j=1,2, \ldots, m, \quad i \neq j,
\end{array}\right.
$$


where

$$
\left|\Sigma^{*}\right|=\left|\begin{array}{lllll}
\sigma_{Y_{1}}^{2}+\sigma_{U_{1}}^{2} & \ldots & \operatorname{cov}\left(Y_{1}, Y_{i}\right) & \ldots & \operatorname{cov}\left(Y_{1}, Y_{m}\right) \\
\ldots & \ldots & \ldots & \ldots & \ldots \\
\operatorname{cov}\left(Y_{i}, Y_{1}\right) & \ldots & \sigma_{Y_{i}}^{2}+\sigma_{U_{i}}^{2} & \ldots & \operatorname{cov}\left(Y_{i}, Y_{m}\right) \\
\ldots & \ldots & \ldots & \ldots & \ldots \\
\operatorname{cov}\left(Y_{m}, Y_{1}\right) & \ldots & \operatorname{cov}\left(Y_{m}, Y_{i}\right) & \ldots & \sigma_{Y_{m}}^{2}+\sigma_{U_{m}}^{2}
\end{array}\right|
$$

The problem (4) will allow an optimal distribution of the $\sigma^{2}$ available resource within the $Y_{i}$ system elements, having independent random variables $U_{i}$ added to them. We can solve this non-linear programming problem using numerical methods. In [15] the theorem is proved.

Theorem 1. Let $\boldsymbol{Y}$ be a normally distributed random vector with a covariance matrix $\Sigma, Y_{1} \sim N\left(a_{i}, \sigma_{i}^{2}\right)$; $-U=\left(U_{1}, U_{2}, \ldots, U_{m}\right)$, a random vector, $U_{i} \sim N\left(a_{U_{i}}, \sigma_{U_{i}}^{2}\right)$. Then the problem (4) has a solution, and any local maximum is global.

Since a system is a set of interrelated elements, in some cases for the problems (3) and (4) we should introduce additional constraints for its elements correlations, like $a \leq|\boldsymbol{R}| \leq b$, which will allow to consider the range of possible correlations within the system.

Let's now consider the problem of minimizing the entropy of a stochastic system. We'll minimize the entropy by reducing the variances of $\boldsymbol{Y}$ random variable's components, which, for some certainty, we'll assume are centered. Based on the random variable's variance properties, its reduction is achieved by dividing the random variable by a positive number. Note, that transition to the changed variance $\sigma_{i}^{2} \rightarrow \sigma_{i}^{2} / x_{i}$ will leave the correlation matrix unchanged.

In this case we have a problem, where we need to optimally reduce the variances of random vector's some components:

$$
\left\{\begin{array}{l}
\frac{1}{2} \log \left[(2 \pi e)^{m} \sigma_{Y_{1}}^{2} \sigma_{Y_{2}}^{2} \ldots \sigma_{Y_{m}}^{2}|\mathbf{R}| / \prod_{i=1}^{l} x_{i}\right] \rightarrow \min _{x_{i}} \\
\sum_{i=1}^{l} x_{i} \leq W, \quad x_{i} \geq 0, \quad i=1,2, \ldots, l
\end{array}\right.
$$

where $|\boldsymbol{R}|$ is the determinant of the correlation matrix, $W$ is the amount of available resource for reducing the variances, $l=1,2, \ldots m$.

The theorem is valid [15].

Theorem 2. Let the $\boldsymbol{Y}$ be a normally distributed random variable with $\boldsymbol{R}$ correlation matrix. Then the solution of problem (5) is $x_{i}=W / l$, where $l$ matches with the maximum value of $\max _{l}\left(\frac{W}{l}\right)^{l}, l=1,2, \ldots m$.

Note, that the problem (5), in fact, suggesting to equally distribute the resource among several or all the system elements, doesn't reveal the growth points (points to impact on the system). Therefore, the minimizing of the system entropy can be considered from the perspective of applying specific management activities to reduce the variances, on 
condition that the changes of $|\boldsymbol{R}|$ will be negligible.

$$
\left\{\begin{array}{l}
\frac{1}{2} \log \left[(2 \pi e)^{m}\left(\sigma_{Y_{1}}^{2}-x_{1}\right)\left(\sigma_{Y_{2}}^{2}-x_{2}\right) \ldots\left(\sigma_{Y_{m}}^{2}-x_{m}\right)|\boldsymbol{R}|\right] \rightarrow \min _{x_{i}} \\
\sum_{i=1}^{m} x_{i} \leq W, \quad 0 \leq x_{i} \leq \sigma_{Y_{i}}^{2}, \quad i=1,2, \ldots, m \\
|\boldsymbol{R}|=\text { const }
\end{array}\right.
$$

The theorem is valid [15].

Theorem 3. Let $\boldsymbol{Y}=\left(Y_{1}, Y_{2}, . ., Y_{m}\right)$ be a Gaussian random vector with $\boldsymbol{R}$ correlation matrix, $Y_{i} \sim N\left(a_{i}, \sigma_{Y_{i}}^{2}\right)$. Then the solution of (6) problem exists, and any local minimum is global.

Let's consider the problems of minimizing and maximizing the system entropy.

The system entropy can also be controlled by strengthening or weakening the correlations between the components, on condition that with such an impact on the system the variances of elements will change negligibly. For instance, when we need to change the entropy towards the reduction of correlations, the problem will have the following form:

$$
\left\{\begin{array}{l}
\frac{1}{2} \log \left[(2 \pi e)^{m}\left|\Sigma^{*}\right|\right] \rightarrow \min _{r_{i j}} \\
a \leq\left|\boldsymbol{R}^{*}\right| \leq b, \quad \boldsymbol{R}^{*} \in D
\end{array}\right.
$$

where $D$ is a set of positive definite correlation matrices with elements $d_{i j},-1<d_{i j}<1$, $d_{i j}=1, \forall i \neq j$.

Let's consider this problem in details. Due to the fact, that $f_{1}(z)=\log (z)$ is a monotonically increasing and concave function, for the objective function (7) it is fair to minimize the part, which is under the logarithm $\operatorname{sign}|\Sigma|=\sigma_{Y_{1}}^{2} \sigma_{Y_{2}}^{2} \ldots \sigma_{Y_{m}}^{2}|\mathbf{R}|$, namely:

$$
\left\{\begin{array}{l}
|\mathbf{R}| \rightarrow \min _{r_{i j}}, \\
a \leq|\mathbf{R}| \leq b, \quad \mathbf{R} \in D, \quad 0 \leq a<b \leq 1
\end{array}\right.
$$

Obviously, the solution of (8) comes to the achievement of to its minimal admissible value a. Theoretically, changing the $r_{i j}$ level of correlations by a certain unit $d_{i j}$ should require attraction of a certain amount of resources $x_{i j}$, therefore the problem of reducing the entropy by impacting on the correlations can be as follows:

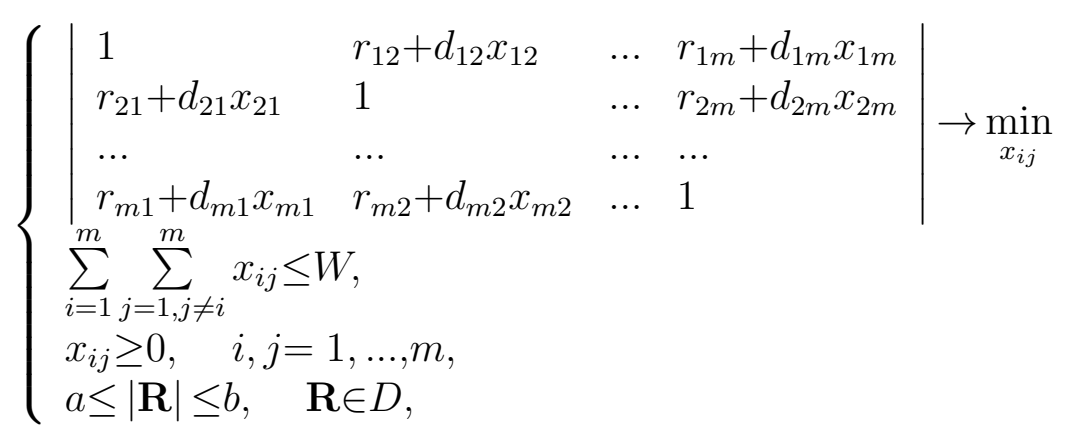

where $W$ is the amount of available resource.

The solution of problem (9) requires a complex work on obtaining and analyzing the statistical information about the change level of correlation depending on the spent 
resources, which is practically very hard to implement. Therefore, it is advisable to consider (8) as a task of identifying the main impact points for applying management actions. As is known, the function gradient is a vector, whose direction points the direction of the fastest increase of the function and the module matches with the highest speed of function change on a certain point. The theorem is valid [15].

Theorem 4. The function $f\left(r_{12}, r_{13}, \ldots, r_{m, m-1}\right)=|\mathbf{R}|, f: D \rightarrow[0 ; 1]$, defined on the set of $D=\left\{\boldsymbol{r} \in R^{m(m-1)}: \quad r_{i j} \in[-1 ; 1], \quad i=\overline{1, m}, \quad j=\overline{i+1, m-1}\right\}$ is convex.

According to theorem 4 to identify the reduction direction of $f\left(r_{12}, r_{13}, \ldots, r_{m, m-1}\right)$ function we can consider the antigradient.

$$
-\operatorname{grad}(f)=-\left(\frac{\partial f}{\partial r_{12}}, \frac{\partial f}{\partial r_{13}}, \ldots, \frac{\partial f}{\partial r_{m,-1}}\right) .
$$

\section{Examples of Entropy Modeling}

Let's consider some examples of entropy modeling.

Example 1. The modeling of a system that characterizes the safety of the production. 17 coal mining enterprises were investigated [15]. According to the system of primary indicators, using factor analysis, two generalized factors (main components) were formed, explaining the $88 \%$ of the entire variation of the initial characteristics: $Y_{1}$ is the factor characterizing the organization of safe production; $Y_{2}$ is the factor reflecting the professionalism of the staff.

All the enterprises were divided into two groups: 1) enterprises with low level of injuries (the coefficient of injury rate in range of 5,8 - 16,5 cases per 1000 person); 2) enterprises with high level of injuries (the coefficient of injury rate in range of $21,7-49,7$ cases per 1000 person). The calculation results by enterprise groups:

$$
\begin{aligned}
& H\left(\boldsymbol{Y}^{(1)}\right)=H\left(\boldsymbol{Y}^{(1)}\right)_{V}+H\left(\boldsymbol{Y}^{(1)}\right)_{R}=2,4166-0,3111=2,1055 \\
& H\left(\boldsymbol{Y}^{(2)}\right)=H\left(\boldsymbol{Y}^{(2)}\right)_{V}+H\left(\boldsymbol{Y}^{(2)}\right)_{R}=3,7360-0,6989=3,0371 .
\end{aligned}
$$

In general, it was found out that the entropy is higher for the second group. For the self-organization entropy $H\left(\boldsymbol{Y}^{(2)}\right)_{R}<H\left(\boldsymbol{Y}^{(1)}\right)_{R}$, the instability of work within the 2nd group to some extent is compensated by more active intervention of the management (the "administrative resource").

Example 2. The modeling of a macroeconomic system [15]. Let's consider the yearly data from Rosstat's collection "Russia in figures" from 2000 to 2013. Using factor analysis, it was found that the initial system can be represented by three factors (main components) $\boldsymbol{Y}=\left(Y_{1}, Y_{2}, Y_{3}\right)$ which explain the $93 \%$ of entire variations of initial characteristics.

We further carry out a comparative analysis of the behavior of macrosystem for two periods (before 2006 (including) and after) using the analysis of entropy of the random vector $\boldsymbol{Y}$. The entropy of macrosystem for first and second periods equals to:

$$
\begin{aligned}
& H\left(\boldsymbol{Y}^{(1)}\right)=H\left(\boldsymbol{Y}^{(1)}\right)_{V}+H\left(\boldsymbol{Y}^{(1)}\right)_{R}=2,02-1,21=0,81 \\
& H\left(\boldsymbol{Y}^{(2)}\right)=H\left(\boldsymbol{Y}^{(2)}\right)_{V}+H\left(\boldsymbol{Y}^{(2)}\right)_{R}=3,19-0,12=3,07 .
\end{aligned}
$$


For the second period a significant increase happened both for randomness entropy $H(\boldsymbol{Y})_{V}$ and the self-organization entropy $H(\boldsymbol{Y})_{R}$. This can speak about the deterioration of the macroeconomics in Russia, as a whole, for the second period, which is caused by the economic crisis and other events in comparison with the fact that the first period was characterized by rather constant growth of economic development of the country.

Example 3. Let's examine the possibilities of entropy modeling on the example of population analysis in terms of preventing chronic non-communicable diseases by biological risk factors [16]. To analyze the change in population entropy depending on the health state, two age groups with equal range were formed: 18-26 years, 27-35 years.

Four risk factors were identified: "Total cholesterol" (TC), "Systolic blood pressure" (SBP), "Body mass index" (BMI), "Blood sugar" (BS). The results of the analysis are shown in the Table.

Table

The entropy levels for groups of "healthy", "practically healthy" and "diseased" people

\begin{tabular}{|c|c|l|l|l|}
\hline Age, years & Health state & $\begin{array}{c}\text { Randomness } \\
\text { entropy }\end{array}$ & $\begin{array}{c}\text { Self- } \\
\text { organization } \\
\text { entropy }\end{array}$ & Total entropy \\
\hline \multirow{3}{*}{$18-26$} & Healthy & 5,500 & $-0,514$ & 4,986 \\
\cline { 2 - 5 } & Practically healthy & 7,131 & $-0,578$ & 6,553 \\
\cline { 2 - 5 } & Diseased & 7,847 & $-0,696$ & 7,151 \\
\hline \multirow{3}{*}{$27-35$} & Healthy & 5,731 & $-0,299$ & 5,432 \\
\cline { 2 - 5 } & Practically healthy & 8,376 & $-0,542$ & 7,834 \\
\cline { 2 - 5 } & Diseased & 8,720 & $-0,781$ & 7,939 \\
\hline
\end{tabular}

With the deterioration of population health state an increase occurs in the total and the randomness entropy, for all the risk factors. This can be explained by the fact that to the pathological influence of risk factors on the human organism individually and to the whole population in general, additional damaging effects of non-communicable diseases are being added.

The self-organization entropy, on the contrary, with the deterioration of the population health, is reduced which means stronger relationships between the subsystems. This can be explained by the idea, that the disease development within the organism doesn't happen isolated. On the other hand, with the disease development some subsystems may adapt to others, compensating the defects in their operating, i.e. some substitution effect can be noted.

Analyzing these examples shows that the entropy management with maximizing and minimizing the system entropy $H(\boldsymbol{Y})$ in a lot of cases can appear to be not effective. Thus, in the examples 1 and 3 the randomness $H(\boldsymbol{Y})_{V}$ and self-organization $H(\boldsymbol{Y})_{R}$ entropies change in different directions. This means that the very scalar formulation of the problem in the form of maximizing (increasing) or minimizing (decreasing) the system entropy $H(\boldsymbol{Y})$ may not be correct. 


\section{Vector Management of Entropy}

In open systems the entropy can both increase and decrease. Moreover, systems with different randomness $H(\boldsymbol{Y})_{V}$ and self-organization $H(\boldsymbol{Y})_{R}$ entropies can have identical values of entropy $H(\boldsymbol{Y})$. Therefore, the management as maximization or minimization (1) may not improve the stochastic system's state, and we'll need to consider the entropy (1) as a vector $h(\boldsymbol{Y})=\left(h_{V} ; h_{R}\right)=\left(H(\boldsymbol{Y})_{V} ; H(\boldsymbol{Y})_{R}\right)$ [11]. In this case the management consists in transforming the system entropy vector from the state of $h\left(\boldsymbol{Y}^{\mathbf{0}}\right)=\left(h_{V}^{0} ; h_{R}^{0}\right)$ to the state of $h\left(\boldsymbol{Y}^{*}\right)=\left(h_{V}^{*} ; h_{R}^{*}\right)$, corresponding to the effective functioning of the stochastic system.

The objective of vector management of the entropy of a Gaussian stochastic system consists in directing the entropy from one initial point $\left(h_{V}^{0} ; h_{R}^{0}\right)=\left(H\left(\boldsymbol{Y}^{0}\right)_{V} ; H\left(\boldsymbol{Y}^{0}\right)_{R}\right)$ with $\Sigma_{0}$ covariance matrix to the $\left(h_{V}^{*} ; h_{R}^{*}\right)$ end point with the minimal changes in covariance matrix (Fig. 1).

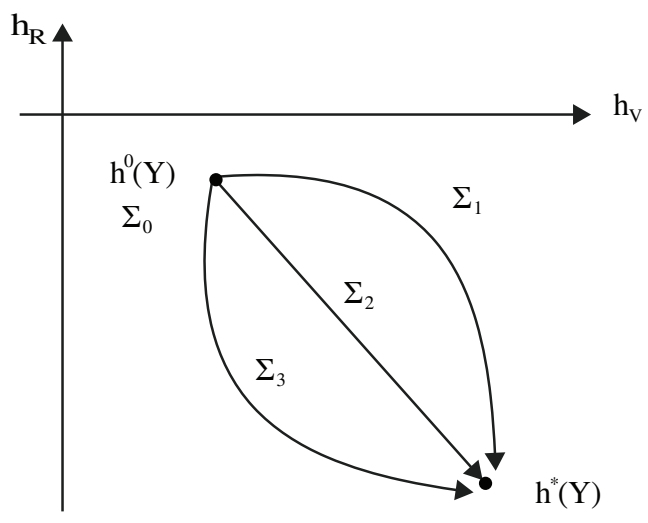

Fig. 1. Entropy estimate dependence on L number of intervals, $H^{*}$ - theoretical value of the entropy

The problem has the following form:

$$
\left\{\begin{array}{l}
G(\Sigma)=\sum_{i=1}^{m} \sum_{j=i}^{m}\left(\sigma_{i j}^{0}-\sigma_{i j}\right)^{2} \rightarrow \min _{\sigma_{i j}}, \\
H(\boldsymbol{Y})_{V}=h_{V}^{*}, \\
H(\boldsymbol{Y})_{R}=h_{R}^{*}, \\
\sigma_{i j}^{2}<\sigma_{i i} \sigma_{j j}, \quad \sigma_{i j}=\sigma_{j i}, \quad \sigma_{i i}>0 \quad \forall 1 \leq i, j \leq m, \\
\Sigma>0 .
\end{array}\right.
$$

The last limitation in (10) shows the positive definition of $\Sigma$ matrix. Note that the efficiency criteria in (10) can differ, depending on the characteristics of specific system S.

The limitations of the non-linear programming problem (10) are not convenient for its algorithmic implementation. Therefore, we transform them:

$$
\begin{gathered}
H(Y)_{V}=\frac{1}{2} \sum_{i=1}^{m} \ln \left(2 \pi e \sigma_{i i}\right)=A, \\
\ln \left((2 \pi e)^{m} \prod_{i=1}^{m} \sigma_{i i}\right)=2 A,
\end{gathered}
$$




$$
\begin{gathered}
\prod_{i=1}^{m} \sigma_{i i}-\frac{e^{2 A-m}}{(2 \pi)^{m}}=0, \\
H(Y)_{R}=\frac{1}{2} \ln \left(\frac{1}{\prod_{i=1}^{m} \sigma_{i i}}|\Sigma|\right)=B \\
\ln \left(\frac{1}{\prod_{i=1}^{m} \sigma_{i i}}|\Sigma|\right)=2 B \\
\frac{1}{\prod_{i=1}^{m} \sigma_{i i}}|\Sigma|-e^{2 B}=0 .
\end{gathered}
$$

As a result, the problem (10) takes the following form:

$$
\left\{\begin{array}{c}
G(\Sigma)=\sum_{i=1}^{m} \sum_{j=1}^{n}\left(\sigma_{i j}-a_{i j}\right)^{2} \rightarrow \min _{\sigma_{\mathrm{ij}}}, \\
\prod_{i=1}^{m} \sigma_{i i}-\frac{e^{2 A-m}}{(2 \pi)^{m}}=0, \\
\frac{1}{\prod_{i=1}^{m} \sigma_{i i}}|\Sigma|-e^{2 B}=0, \\
\sigma_{i j}^{2}<\sigma_{i i} \sigma_{j j}, \quad \sigma_{i j}=\sigma_{j i}, \sigma_{i i}>0 \forall 1 \leq i, j \leq m, \\
\Sigma>0 .
\end{array}\right.
$$

We find the derivatives of the constraints of problem (11). For the first constraint, we have:

$$
\begin{gathered}
g_{1}(\Sigma)=\prod_{i=1}^{m} \sigma_{i i}-\frac{e^{2 A-m}}{(2 \pi)^{m}}=0, \\
\frac{\partial g_{1}}{\partial \sigma_{i j}}= \begin{cases}0, & i \neq j, \\
\prod_{k \neq i} \sigma_{k k}, & i=j .\end{cases}
\end{gathered}
$$

Let's consider the second constraint:

$$
g_{2}(\Sigma)=\frac{1}{\prod_{i=1}^{m} \sigma_{i i}}|\Sigma|-e^{2 B}=0 .
$$

Let's find the partial derivatives of the function $g_{2}(\Sigma)$ :

$$
\frac{\partial g_{2}}{\partial \sigma_{i j}}=\left\{\begin{array}{ll}
\frac{1}{\prod_{k=1}^{m} \sigma_{k k}} \cdot|\Sigma|_{\sigma_{i j}}^{\prime}, & i \neq j, \\
\frac{1}{\prod_{k \neq i} \sigma_{k k}}\left(-\frac{1}{\sigma_{i i}^{2}}|\Sigma|+\frac{1}{\sigma_{i i}}|\Sigma|_{\sigma_{i i}}^{\prime}\right), & i=j,
\end{array}=\right.
$$




$$
\begin{aligned}
& = \begin{cases}\frac{1}{\prod_{k=1}^{m} \sigma_{k k}} \cdot\left(A_{i j}+A_{j i}\right), & i \neq j, \\
\frac{1}{\prod_{k \neq i} \sigma_{k k}}\left(-\frac{1}{\sigma_{i i}^{2}}|\Sigma|+\frac{1}{\sigma_{i i}} A_{i i}\right), & i=j,\end{cases} \\
& = \begin{cases}\frac{1}{\prod_{k=1}^{m} \sigma_{k k}} \cdot\left(A_{i j}+A_{j i}\right), & i \neq j, \\
\frac{1}{\prod_{k=1}^{m} \sigma_{k k}}\left(A_{i i}-\frac{1}{\sigma_{i i}} \cdot|\Sigma|\right), & i=j .\end{cases}
\end{aligned}
$$

The problem (11) will be solved using the penalty methods [17]. Moreover, the minimum of the merit functions can be found by numerical methods of searching for an any order unconditional extremum.

Let's consider the particular case of two-dimensional Gaussian stochastic system $\boldsymbol{Y}=\left(Y_{1}, Y_{2}\right)$ with covariance matrix $\Sigma=\left\{\sigma_{i j}\right\}_{2 \times 2}$. Then the entropy of $\boldsymbol{Y}$ vector, according to (2), will be:

$$
H(\boldsymbol{Y})=H(\boldsymbol{Y})_{V}+H(\boldsymbol{Y})_{R}
$$

where

$$
\begin{aligned}
H(\boldsymbol{Y})_{V} & =\frac{1}{2} \log \left[(2 \pi e)^{2} \sigma_{11} \sigma_{22}\right], \\
H(\boldsymbol{Y})_{R} & =\frac{1}{2} \log \left[1-\frac{\sigma_{12}^{2}}{\sigma_{11} \sigma_{22}}\right] .
\end{aligned}
$$

As a result, the problem (10) will look:

$$
\left\{\begin{array}{l}
G(\Sigma)=\sum_{i=1}^{2} \sum_{j=i}^{2}\left(\sigma_{i j}^{0}-\sigma_{i j}\right)^{2} \rightarrow \min _{\sigma_{i j}} \\
\frac{1}{2} \log \left[(2 \pi e)^{2} \sigma_{11} \sigma_{22}\right]=h_{V}^{*} \\
\frac{1}{2} \log \left(1-\frac{\sigma_{12}^{2}}{\sigma_{11} \sigma_{22}}\right)=h_{R}^{*} \\
\sigma_{12}=\sigma_{21}, \quad \sigma_{i i}>0, \quad i=1,2 .
\end{array}\right.
$$

Example 4. Let the $\boldsymbol{Y}^{\mathbf{0}}$ have a covariance matrix of:

$$
\Sigma_{0}=\left(\begin{array}{ll}
1,87 & 1,63 \\
1,63 & 2,08
\end{array}\right)
$$

for it $H\left(\boldsymbol{Y}^{0}\right)=2,93, \mathrm{H}\left(\mathbf{Y}^{0}\right)_{\mathrm{V}}=3,515, \mathrm{H}\left(\mathbf{Y}^{0}\right)_{\mathrm{R}}=-0,585$.

We'll change the covariance matrix to be:

$$
\Sigma_{1}=\left(\begin{array}{ll}
1,87 & 1,63 \\
1,63 & 2,58
\end{array}\right)
$$

for which $H\left(\boldsymbol{Y}^{1}\right)=3,22, H\left(\boldsymbol{Y}^{1}\right)_{V}=3,62, H\left(\boldsymbol{Y}^{1}\right)_{R}=-0,39$.

Let's estimate the change of covariance matrix: $\Delta=(2,58-2,08)^{2}=0,5^{2}=0,25$. 
Now let's move from the initial $\left(h_{V}^{0} ; \quad h_{R}^{0}\right)=(3,515 ;-0,585)$ state to the state of $\left(h_{V}^{*} ; \quad h_{R}^{*}\right)=(3,62 ; \quad-0,39)$, using optimization problem (12). As a result of problem (12) solution, we have a new covariance matrix:

$$
\Sigma^{*}=\left(\begin{array}{ll}
2,09 & 1,608 \\
1,608 & 2,28
\end{array}\right)
$$

Let's estimate the change of covariance matrix:

$$
G\left(\Sigma^{*}\right)=(2,09-1,87)^{2}+(1,608-1,63)^{2}+(2,28-2,08)^{2}=0,089 .
$$

Example 5. Let's go on with the example 1. For the first group of coal mining companies with low level of injuries we have:

$$
\begin{gathered}
\Sigma^{(1)}=\left(\begin{array}{cc}
0,0671 & 0,4466 \\
0,4466 & 6,4138
\end{array}\right), \\
\left(h_{V}^{(1)} ; \quad h_{R}^{(1)}\right)=(2,4166 ;-0,3111), \\
H\left(\boldsymbol{Y}^{(1)}\right)=2,1055 .
\end{gathered}
$$

For the second group of coal mining enterprises with high level of injuries:

$$
\begin{gathered}
\Sigma^{(2)}=\left(\begin{array}{ll}
0,3253 & 2,1302 \\
2,1302 & 18,5289
\end{array}\right), \\
\left(h_{V}^{(2)} ; \quad h_{R}^{(2)}\right)=(3,7360 ; \quad-0,6989), \\
H\left(\boldsymbol{Y}^{(2)}\right)=3,0371 .
\end{gathered}
$$

Solving the problem (12) in this form:

$$
\left\{\begin{array}{l}
G(\Sigma)=\sum_{i=1}^{2} \sum_{j=i}^{2}\left(\sigma_{i j}^{(2)}-\sigma_{i j}\right)^{2} \rightarrow \min _{\sigma_{i j}} \\
\frac{1}{2} \log \left[(2 \pi e)^{2} \sigma_{11} \sigma_{22}\right]=h_{V}^{(1)} \\
\frac{1}{2} \log \left(1-\frac{\sigma_{12}^{2}}{\sigma_{11} \sigma_{22}}\right)=h_{R}^{(1)} \\
\sigma_{12}=\sigma_{21}, \quad \sigma_{i i}>0, \quad i=1,2
\end{array}\right.
$$

we'll have:

$$
\begin{gathered}
\Sigma^{*}=\left(\begin{array}{ll}
0,0232 & 0,4466 \\
0,4466 & 18,5285
\end{array}\right), \\
\left(h_{V}^{*} ; \quad h_{R}^{*}\right)=(2,4166 ;-0,3111), \\
H\left(\boldsymbol{Y}^{*}\right)=2,1055 .
\end{gathered}
$$

The change of covariance matrix is:

$$
\begin{aligned}
& G\left(\Sigma^{*}\right)=(0,0232-0,3253)^{2}+(0,4466-2,1302)^{2}+ \\
& +(18,5285-18,5289)^{2}=2,9258
\end{aligned}
$$


Then, solving the minimization problem

$$
\left\{\begin{array}{l}
H(\boldsymbol{Y})=\frac{1}{2} \ln \left[(2 \pi e)^{m}|\Sigma|\right] \rightarrow \min _{\sigma_{i j}}, \\
\sum_{i=1}^{2} \sum_{j=i}^{2}\left(\sigma_{i j}^{(2)}-\sigma_{i j}\right)^{2} \leq 2,9258 \\
\sigma_{11} \sigma_{22}>\sigma_{12}^{2} \\
\sigma_{12}=\sigma_{21}, \quad \sigma_{i i}>0, \quad i=1,2
\end{array}\right.
$$

we'll have:

$$
\begin{gathered}
\Sigma^{* *}=\left(\begin{array}{ll}
0,1651 & 1,7439 \\
1,7439 & 18,4891
\end{array}\right), \\
\left(h_{V}^{* *} ; h_{R}^{* *}\right)=(3,3959 ; \quad-2,7779), \\
H\left(\mathbf{Y}^{* *}\right)=0,6180 .
\end{gathered}
$$

We can see that the solutions of (12) and (14) are significantly different.

The (13) solution of problem (12) gives a result, allowing with the minimal change of $\Sigma^{(2)}$ covariance matrix elements, realize the entropy management.

The obtained (15) solution of problem (14) doesn't correspond to the admissible values of randomness and self-organization entropies. Indeed, the randomness entropy $H\left(\boldsymbol{Y}^{* *}\right)_{V}=3,3959$ turned to be too high, and the self-organization entropy $H\left(\boldsymbol{Y}^{* *}\right)_{R}=-2,7779-$ to be too low compared with the required values.

\section{Conclusion}

1. Problems of entropy management for Gaussian stochastic systems were considered in scalar form (based on the concept of "growth points") and in vector form.

2. It was demonstrated that the scalar management of entropy for a number of cases turns to be ineffective.

3. Some examples are considered for Gaussian stochastic systems; the objective of entropy management was formed. An example of solving the entropy management problems for two-dimensional random vector was introduced.

The reported study was funded by RFBR according to the research project № 17-01-00315a.

\section{References}

1. Prangishvili I.V. Entropy and Other System Regularities: Control Problems of Complicated Systems. Moscow, Nauka Publ., 2003. (in Russian)

2. Wilson A.J. [Entropy Methods of Modeling of Complicated Systems]. Moscow, Fizmatlit Publ., 1978. (in Russian)

3. Skorobogatov S.M. Catastrophes and Serviceability of Reinforced Concrete Buildings (Classication and Elements of the Theory). Ekaterinburg, Ural State University of Railway Transport, 2009. (in Russian)

4. Prits A.K. [Principle of Stationary Conditions of Open Systems and Dynamics of Populations]. Kaliningrad, Kaliningrad State University, 1974. (in Russian) 
5. Haken H. Information and Self-Organization- A Macroscopic Approach to Complex Systems. Berlin, Heidelberg, Springer-Verlag, 2006. doi: 10.1119/1.15809.

6. Hazen A.M. [Introduction of a measure of information to axiomatic base of mechanics]. Moscow: RAUB Publ., 1998. (in Russian)

7. Timashev S.A., Tyrsin A.N. Entropy Approach to Risk-Analysis of Critical Infrastructure Systems. The First International Conference on Vulnerability and Risk Analysis and Management and the Fifth International Symposium on Uncertainty Modeling and Analysis. Proceedings of the ICVRAM 2011 and ISUMA 2011 Conferences. Maryland, United States, American Society of Civil Engineers, 2011, pp. 147-154. doi: 10.1061/41170(400)18.

8. Popkov Yu.S. [Mathematical Demoeconomics: Macrosystem Approach]. Moscow, LENAND Publ., 2013. (in Russian)

9. Shannon C.E. A Mathematical Theory of Communication. The Bell System Technical Journal, 1948, vol. 27, no. 3, pp. 379-423, no. 4, pp. 623-656. doi: 10.1002/j.15387305.1948.tb01338.x.

10. Cover T.M., Thomas J.A. Elements of Information Theory. New York, Wiley, 1991.

11. Tyrsin A.N., Sokolova I.S. Entropy-Probabilistic Modeling of Gaussian Stochastic Systems. Mathematical modeling, 2012, vol. 24, no. 1, pp. 88-103. (in Russian)

12. Kondepudi D., Prigogine I. Modern Thermodynamics: From Heat Engines to Dissipative Structures. New York, Wiley, 1999.

13. Klimontovich Yu.L. An Introduction to the Physics of Open Systems. Moscow, YanusK Publ., 2002. (in Russian)

14. Perroux F. L'économie du XXe siècle. Paris, Presses Universitaires de France, 1969.

15. Tyrsin A.N. [Entropy Modeling of Multidimensional Stochastic Systems]. Voronezh, Nauchnaya Kniga Publ., 2016.

16. Tyrsin A.N., Kalev O.F., Yashin D.A., Lebedeva O.V. Assessment of Health Status of a Population on the Basis of Entropy Modeling. Mathematical Biology and Bioinformatics, 2015, vol. 10. issue 1. pp. 206-219. doi: 10.17537/2015.10.206. (in Russian)

17. Panteleev A.V., Letova T.A. [Optimization Methods in Examples and Problems]. Moscow, Vysshaia Shkola Publ., 2008.

Alexander N. Tyrsin, DSc (Techn), Head of Department of Applied Mathematics, Ural Federal University named after the first President of Russia B.N. Yeltsin (Ekaterinburg, Russian Federation), at2001@yandex.ru.

Garnik G. Gevorgyan, Graduate Student, Department of Applied Mathematics, Ural Federal University named after the first President of Russia B.N. Yeltsin (Ekaterinburg, Russian Federation), garnik.ggg@gmail.com.

Received November 1, 2017 


\title{
ЭНТРОПИЙНОЕ УПРАВЛЕНИЕ ГАУССОВСКИМИ СТОХАСТИЧЕСКИМИ СИСТЕМАМИ
}

\author{
А.Н. Тырсин, Г.Г. Геворгян
}

\begin{abstract}
Рассмотрены два подхода к энтропийному управлению гауссовскими стохастическими системами. Первый подход является скалярным и реализует концепцию кточек ростањ. При этом решается задача максимизации (увеличения) или минимизации (уменьшения) энтропии системы. Второй подход представляет собой векторное управление, позволяющее обеспечить эффективное изменение энтропии как двумерного вектора, компонентами которого являются энтропии хаотичности и самоорганизации. Для векторного управления сформулирована оптимизационная задача на условный экстремум. Данная задача может быть решена методами штрафных функций. Показано, что в ряде случаев векторное энтропийное управление имеет преимущества по сравнению со скалярным управлением. Приведены примеры энтропийного управления для реальных стохастических систем.

Ключевые слова: дифференииальная энтропия, модель, многомерная случайная величина, гауссовская стохастическая система, ковариационная матрица, управление, вектор, хаотичность, самоорганизация.
\end{abstract}

\section{Литература}

1. Прангишвили, И.В. Энтропийные и другие системные закономерности: Вопросы управления сложными системами / И.В. Прангишвили. - М.: Наука, 2003.

2. Вильсон, А.Дж. Энтропийные методы моделирования сложных систем А.Дж. Вильсон. - М.: Физматлит, 1978.

3. Скоробогатов, С.М. Катастрофы и живучесть железобетонных сооружений (классификация и элементы теории) / С.М. Скоробогатов. - Екатеринбург: Уральский гос. ун-т путей сообщ., 2009.

4. Приц, А.К. Принцип стационарных состояний открытых систем и динамика популяций / А.К. Приц. - Калиниград: Калининградский государственный университет, 1974.

5. Haken, H. Information and Self-Organization: A Macroscopic Approach to Complex Systems / H. Haken. - Berlin, Heidelberg: Springer-Verlag, 2006.

6. Хазен, А.М. Введение меры информации в аксиоматическую базу механики А.М. Хазен. - М.: РАУБ, 1998.

7. Timashev, S.A. Entropy Approach to Risk-Analysis of Critical Infrastructure Systems / S.A. Timashev, A.N. Tyrsin // The First International Conference on Vulnerability and Risk Analysis and Management and the Fifth International Symposium on Uncertainty Modeling and Analysis. Proceedings of the ICVRAM 2011 and ISUMA 2011 Conferences. - Maryland, United States: American Society of Civil Engineers, 2011. - P. 147-154. 
8. Попков, Ю.С. Математическая демоэкономика: Макросистемный подход Ю.С. Попков. - М.: ЛЕНАНД, 2013.

9. Shannon, C.E. A Mathematical Theory of Communication / C.E. Shannon // The Bell System Technical Journal. - 1948. -V. 27, №. 3. - P. 379-423. - №. 4. - P. 623-656.

10. Cover, T.M. Elements of Information Theory / T.M. Cover, J.A. Thomas. - New York: Wiley, 1991.

11. Тырсин, А.Н. Энтропийно-вероятностное моделирование гауссовских стохастических систем / А.Н. Тырсин, И.С. Соколова // Математическое моделирование. 2012. - T. 24 , № 1, - C. 88-103.

12. Kondepudi, D. Modern Thermodynamics: From Heat Engines to Dissipative Structures / D. Kondepudi, I. Prigogine. - New York: Wiley, 1999.

13. Климонтович, Ю.Л. Введение в физику открытых систем / Ю.Л. Климонтович. М.: Янус-К, 2002.

14. Perroux, F. L'économie du XXe siècle / F. Perroux. - Paris: Presses Universitaires de France, 1969.

15. Тырсин, А.Н. Энтропийное моделирование многомерных стохастических систем / А.Н. Тырсин. - Воронеж: Научная книга, 2016.

16. Тырсин, А.Н. Оценка состояния здоровья популяции на основе энтропийного моделирования / А.Н. Тырсин, О.Ф. Калев, Д.А. Яшин, О.В. Лебедева // Математическая биология и биоинформатика. - 2015. - Т. 10, Вып. 1, - С. 206-219.

17. Пантелеев, А.В. Методы оптимизации в примерах и задачах / А.В. Пантелеев, Т.А. Летова. - М.: Высшая школа, 2008.

Тырсин Александр Николаевич, доктор технических наук, заведующий кафедрой прикладной математики, Уральский федеральный университет имени первого Президента России Б.Н. Елъцина (г. Екатеринбург, Российская Федерачия), at2001@yandex.ru.

Геворгян Гарник Гургенович, аспирант, кафедра прикладной математики (Уральский Энергетический Институт), Уральский федеральный университет имени первого Президента России Б.Н. Ельиина (г. Екатеринбург, Российская Федераuия),garnik.ggg@gmail.com.

Поступила в редакцию 1 ноября 2017 г. 